\title{
"ABRAM OS PORTÕES DO VALE: EU VOU ENTRAR" \\ Funk LGBTTQIA+, currículos escolares, estéticas e educação musical
}

\author{
"ABRAMOS LOS PUERTOS DEL VALLE: YO VOY ENTRAR" \\ Funk LGBTTQIA+, currículos escolares, estéticas y educación musical
}

\author{
"OPEN THE VALLEY GATES: I WILL ENTER" \\ Funk LGBTTQIA +, schoolar curriculum, aesthetics and music education
}

Wenderson Oliveira

\begin{abstract}
RESUMO
Este trabalho pretende discutir a interseção entre a produção do funk para e pelo público LGBTTQIA+, currículos escolares, estéticas juvenis e educação musical. Procuramos, por meio de um escopo teórico, discutir sobre os dispositivos curriculares da educação básica, propomos um olhar ao funk como meio de fruir, existir e resistir no espaço escolar. Acreditamos que, na escola, essa veiculação sonora permite que haja uma resistência ao assujeitamento e ao binarismo no qual somos conduzidos socialmente e ainda presente nos discursos educacionais formalizados, criando, portanto, uma estética da existência.
\end{abstract}

PALAVRAS-CHAVE: cotidiano escolar, dispositivos curriculares, estéticas juvenis, juventude LGBT, música gay

\section{RESUMEN}

Este trabajo pretende discutir la intersección entre la producción del funk para y por el público LGBTTQIA+, currículos escolares, estéticas juveniles y educación musical. Buscamos, por medio de un alcance teórico, discutir sobre los dispositivos curriculares de la educación básica, proponemos una mirada al funk como medio de frucir, existir y resistir en el espacio escolar. Creemos que, en la escuela, esa transmisión sonora permite que haya una resistencia al asolamiento y al binarismo en el que somos conducidos socialmente y aún presente en los discursos educativos formalizados, creando, por lo tanto, una estética de la existencia.

PALABRAS CLAVE: cotidiano escolar, dispositivos curriculares, estéticas juveniles, juventud LGBT, música gay

\begin{abstract}
This work intends to discuss the intersection between funk production for and by the LGBTTQIA+ public, schoolar curriculum, youth aesthetics and music education. We seek, through a theoretical scope, to discuss the curricular devices of basic education, we propose a look at funk as a means of enjoying, existing and resisting in the school space. We believe that, in school, this sonic transmission allows a resistance to the subjection and binarism in which we are socially conducted and still present in the formalized educational discourses, thus creating an aesthetic of existence.

KEYWORDS: everyday life and school, curricular devices, youth aesthetics, LGBT youth, gay music
\end{abstract}


Reclamam do jeito que eu dou risada Reclamam da minha mão desmunhecada Reclamam do jeito que jogo o cabelo pra trás E dizem que a minha voz é bem miada Que não precisa ser tão afeminada Precisa sim! Eu vou continuar assim... Afeminada

$[C t r l+N-$ Afeminada]

Há um considerável número de estudos que se debruçam sobre os enredamentos e tramas que circunscrevem a juventude, bem como os entrelaces de seus fluxos culturais, os modos de ser, estar e viver no mundo cotidiano e na escola. Os deslocamentos da juventude nos múltiplos espaços-tempos de nossas escolas, abrem campo para que possamos pensar a diversidade presente nos lugares (CARLOS, 2007) em que esse público se apresenta e, do mesmo modo, nos faz indagar sobre as sociabilidades vividas e construídas nos tempos-espaços que formamos e nos quais somos formados.

Percorrendo a literatura sobre juventude e música, encontramos significativos trabalhos que nos convidam a adentrar no complexo mundo de sentidos, identidades, efemeridades, resiliências, existências e resistências. Arroyo (2013), por exemplo, mapeou parte dessa literatura, ao todo 150 títulos nacionais e estrangeiros, segundo a autora, publicados entre 1996 e 2011. Investigar as práticas musicais dos/das jovens é também, na visão de Arroyo, tentar compreender a sociedade contemporânea, as práticas e usos (CERTEAU, 1998) dos fluxos culturais como criação de uma identidade. Identidade esta que não é permanente, mas transitória e de experiências de constantes (trans)formações. Esses fluxos culturais podem ser entendidos como um “espaço privilegiado de práticas, representações, símbolos e rituais no qual os jovens buscam demarcar uma identidade juvenil" (DAYRELL, 2002, p.119). Nesse sentido, este trabalho procura dialogar com uma das transitoriedades identitárias de (trans)form(ações) juvenis, tentando entender a música praticada para a juventude como uma dimensão simbólica de pertencimento a determinado grupo. Esse pertencimento identitário é responsável por tecer escutas e gestos musicais que, no ambiente escolar, são partilhados nas inúmeras relações construídas e constituídas 
nos cotidianos educacionais, numa ação constante que se urde dentro-fora/fora-dentro dos ambientes institucionalizados da prática educativa.

Consideramos que uma das expressões que vem marcando a pluralidade escolar e seus processos de identidade, sem dúvidas, é a diversidade sexual, diversidade que engloba de maneira inclusiva os sexos, orientações sexuais e identidades de gênero. Entre os jovens, essa diversidade é um traço forte que vem (re)configurando os dispositivos que antes regulavam a escola. Escola esta que se circunscrevia numa [vã] tentativa de uniformidade - encontrada em diversos artefatos como uniformes escolares adequados ao binarismo sexual feminino/masculino, práticas sexuais binárias como brinquedos/brincadeiras de meninas e meninos, dentre outros que ajustam nossa forma de pensar as imagens escolares e viver a prática educativa dentro desses ambientes.

Tentando mostrar esse constante movimento juvenil, em suas variadas experiências para produzir e organizar sua identidade - contingente em constante mutação - nos desdobramos a pensar a diversidade sonora que se apresenta nos cotidianos escolares como forma de resistência à regulação do que deve (ou não) ser aprendido na educação formalizada e legitimado como saber institucionalizado. A maneira que escolhemos para pensar essa multiplicidade foi recorrer às escutas da música funk produzida pelo e para o público LGBTTQIA+1 e suas formas de ser/estar nos currículos escolares.

A escolha desse repertório não é ao acaso, pelo contrário, notamos que, atualmente, a música funk tornou-se um dos palcos que mais tem contribuído de forma significativa para os intérpretes LGBTTQIA+. "São letras e vozes que nos permitem visualizar o protagonismo juvenil e seus embates em meio à teia das relações sociais que fazem de sua cidade" (VICTORIO FILHO, 2008, p.216). Estas músicas, que se constituem como canções com poesias particulares são caracterizadas, especialmente, por narrativas que incluem os cotidianos de jovens que passam por diversas cenas, algumas delas de agressão física, psicológica e expurgo social. Muitas dessas narrativas compõem os cotidianos de seus intérpretes, suas formas de relacionarem-se

\footnotetext{
1 Sigla correspondente à: Lésbicas, Gays, Bissexuais, Travestis, Transexuais, Queer, Intersexuais, Assexuados, o +: agênero, pansexuais, polisexuais, simpatizantes, dentre outros.
} 
com o mundo, suas experiências, a condição social, seus corpos e as traduções de suas imagens que sempre estão em posição de transgressão, mesmo que, em princípio, essa transgressão não se mostre de maneira clara. Destacadas principalmente na internet, artistas como Mulher Pepita, Linn da Quebrada, Gloria Groove, Lia Clark, Pabllo Vittar, Aretuza Lovi, Kaya Conky, Ctrl+N, são algumas das vozes que ocupam notoriedade nas plataformas digitais e nas escutas juvenis.

Essas vozes atraem milhares de seguidores, ouvintes e também coautores de uma estética que pretende ir além do ato de dar voz (e vez) a um público que se encontra historicamente marginalizado por uma sociedade normativa que, pautada numa conduta moral-ideológica-cristã, é responsável por configurar nossos saberes escolares, aquilo que é considerado saudável para nossas escutas e práticas musicais e a maneira considerada correta de ser e estar no mundo. Prática esta que elucubra um binarismo sexual selvagem que elege uns e marginaliza outros em detrimento de uma corrente de pensamento decrépita, a qual, ao chegar em nossas escolas, germina uma onda de manifestações (pré)conceituosas que cristalizam uma visão de estética, descartando e criminalizando aquilo que não é produzido nos espaços instituídos e outorgados como legítimos da produção artística (VICTORIO FILHO, 2008).

Empenhados em caminhar na contramão disso e ler os espaços nos quais nos inserimos, começamos a notar nos grupos sociais que costumamos ter contato, a predileção dos/das jovens, sobretudo LGBTTQIA+, por essas peculiares músicas e intérpretes, de modo que o conhecimento estético-musical que essas pessoas levam à escola perpassa, dentre outros, também por esse repertório. Essas condições de pertencimento que promovem essas dinâmicas nas estruturas identitárias juvenis são responsáveis por criar estéticas de existência (MISKOLCI, 2006), um nomadismo artístico, um trânsito musical, que é responsável por deslocar o que entendemos que deva ser ensinado nas escolas, ou aquilo que consideramos legítimo para que seja apre(e)ndido pelos/pelas estudantes. Assim como, (des)estrutura o currículo escolar, fazendo com o que o mesmo seja vivido de modo quase oposto ao pensado, criando fendas ao que é imposto, numa tentativa de deixar a vida escolar apraz.

O debate proposto é de natureza teórica, no qual abrange estudos bibliográficos sobre a proposta investigativa. Além disso, leva-se em consideração as experiências e 
vivências docentes nas escolas públicas e as pesquisas desenvolvidas anteriormente, que tem como olhar central a educação musical escolar e a promoção da equidade educacional.

\section{'Cheguei, tô preparada pra atacar': uma bicha' na escola}

'Sua Cara', um clipe produzido pelo DJ Major Lazer e com as cantoras Anitta e Pabllo Vittar, em agosto do ano de 2017, atinge 20 milhões de pessoas em 24 horas de lançamento, se tornando um dos mais procurados e vistos na história da plataforma YouTube. O clipe entra nas escolas, o clipe circula dentro delas, está no corpo dos praticantes do cotidiano, está nas imagens e sons que as/os alunas/alunos levam consigo. Uma drag queen ocupa um lugar, subvertendo a outorga dos espaços legitimados para a Arte. Aqui, comemoro, tomo meu lugar enquanto artista homossexual, ou melhor, artista bicha, docente, que está inserido nos movimentos contínuos do espaço escolar e que, junto aos que estão fora e dentro dele, forma as redes de saberes, redes estas que me (trans)formam e que, agora, (com)partilho, (des)armo.

Indo ao encontro de Takara (2017b), quando decido chamar-me de bicha em um texto acadêmico, tento fender as prisões que a Modernidade produziu na escrita científica. Tomar um lugar de fala enquanto bicha artista em um texto acadêmico me afasta da pretensa intenção de alguém que escreve sobre algo, mas sim, com ele. Nesse sentido, o caminho teórico-epistemológico se envereda pelas estradas da pesquisa nos/dos/com cotidianos (ALVES, OLIVEIRA, 2001), no qual, efetivamente, acredito que "há um modo de fazer e de criar conhecimento no cotidiano, diferente daquele aprendido, na modernidade, especialmente, e não só, com a ciência” (ALVES, 2001, p.14). Seguindo essa premissa, a proposta da escrita em primeira pessoa é singrar com uma forma fechada de sentir o mundo e de nele pesquisar, fazendo coro com Nilda Alves (2001) que nos ensina que é necessário, para assumir "novas preocupações,

\footnotetext{
${ }^{2}$ Quando proponho utilizar este termo, assim como o autor, tenho ciência das diferentes formas de tratamento entre homossexuais masculinos. Nas palavras do autor, ele entende que "a bicha por produtiva porque registra outros modos de olhar às formas de vida dos homens afeminados homossexuais que não se sentem incluídos em diferentes categorias que são registradas para distanciar essa experiência de outras formas de ser gay. Neste terreno de disputas, vejo a bicha como potencial estratégico, mas entendo que a pluralidade é possível" (TAKARA, 2017a, p.12).
} 
novos problemas, novos fatos e novos achados [...] uma nova maneira de escrever, que remete a mudanças muito mais profundas. A esse movimento talvez se pudesse chamar de narrar a vida e literaturizar a ciência” (ALVES, 2001, p. 16). Portanto, assim como Takara (2017b), "chamo-me de bicha para afastar o/a leitor/a curioso do conforto de pensar-me como um colega que redige um texto e coloco-me como alguém que trabalhando com um material documental, emprega métodos e técnicas, no intuito de descobrir algo" (TAKARA, 2017b, p.2). Desta forma, construo este texto.

No início deste trabalho, em forma de epígrafe, cito MC Linn da Quebrada, na canção Bixa Preta, a qual (re)monta a cena de uma bicha da favela, afeminada, negra, que bravamente resiste às condições binárias impostas, principalmente à masculinidade hegemônica, branca, cisgênero e heterossexual (OLIVEIRA, 2017). Essa marginalidade social representada pela cantora é a mesma, em outros ângulos, da enfrentada pelos/pelas estudantes LGBTTQIA+ nas escolas públicas. Veiga (2008) nos lembra que durante 60 anos no século XX, a escola pública era destinada a pessoas das classes média e alta e não às classes menos favorecidas, assim como, essas vagas eram destinadas, em sua maioria, às pessoas brancas. A mudança no sistema educacional público brasileiro é decorrente, segundo Algebaile (2004), de uma série de processos contínuos e descontínuos e nem sempre lineares e, no meio dessas (tras)formações com o passar dos anos, encontramos a inserção da bicha na escola.

Partilho da asserção de OLIVEIRA (2017, p.101): "seguir os passos da bicha não é uma tarefa das mais simples. Exige um caminhar titubeante pelas bordas e um mergulho por frestas escuras onde é constantemente alocada”. Na escola, a bicha é constantemente colocada nos espaços foscos, nos quais, é necessário cumprir uma série de normas, de vedações corpóreas, de falas e gestos que não só violentam fisicamente, mas, simbolicamente. Vivemos imersos em fluxos culturais que nos impõe - nas múltiplas relações interpessoais, midiáticas, dentre outras - constantemente a ideia de um masculino/feminino, calabouços que, de tão oclusos, exterminam aquilo que é considerado diferente. "A construção das identidades de gênero é uma aprendizagem que se realiza nas relações de negociação com os significados dos processos, das práticas e das leituras de discursos que estão imersos nas significações das culturas" (TAKARA, 2017c, p.227), ou seja, no movimento dentro-fora/fora-dentro das escolas, 
são (des)construídas e (des)constituídas essas relações de gênero e sexualidade(s) e nelas temos dois caminhos: o da liberdade ou da asfixia, asfixia que provoca uma morte silenciosa e meticulosamente precisa.

As violências nas quais a bicha é submetida no ambiente escolar as convida, diariamente, a retirarem-se do espaço que, nitidamente, não é conferido a elas. Se voltarmos uns anos, especificamente em 2011, quando o Governo Federal lança o material didático, Escola sem Homofobia - apelidado pela bancada evangélica de kit gay - que tratava de temas como homossexualidade, transexualidade e bissexualidade e se direcionava para o público jovem, com o objetivo de debater sobre gênero e sexualidade no ambiente escolar, lembraremos das críticas e polêmicas, por parte dos setores mais conservadores do Congresso Nacional e da população brasileira. Esses mesmos olhares insidiosos para o material didático destinado às múltiplas discussões acerca de temas tão caros e urgentes à educação pública, principalmente, são os mesmos que pregam a ideia da ideologia de gênero - e por consequência, a tentativa de seu desmonte.

A ideologia de gênero é uma das principais tentativas de desmontar a educação pública brasileira. Segundo Reis e Eggert (2017), ao criar a falaciosa ideologia de gênero, põe-se em prática os argumentos de destruição da família tradicional, incitação e legalização da pedofilia e o fim da ordem natural e relações normais entre gêneros e, com isso, "nega a existência da discriminação e violência contra mulheres e pessoas LGBT comprovadas com dados oficiais e estudos científicos” (REIS; EGGERT, 2017, p.20). Desse modo, como menciona os autores, foi criado um intenso movimento que varreu as discussões sobre gênero e sexualidade dos currículos escolares, fazendo com que, novamente, a bicha voltasse para a clandestinidade.

A bicha na escola, representada pelos fugazes, proibidos e temidos sons que ecoam nas marginalidades das produções cotidianas, é a percepção da figura feminina em corpos machos, contrapondo aquilo que foi ajustado socialmente e culturalmente, como nos aponta Takara (2017a) como homem. Se enveredarmos a pensar que o que entendemos como fluxo cultural é um discurso, ou seja, "um modo de construir sentidos que influencia e organiza tanto nossas ações quanto a concepção que temos de nós mesmos" (HALL, 2006, p.50), perceberemos que as construções musicais escolares, 
produtos de nossas vivências dentro e fora dos espaços, são, num amplo sentido, construções coletivas que são implantadas nos sujeitos na aula de música, de modo que esse sujeito esteja passivo à recepção de determinados conjuntos de símbolos e deles fecunde sua individualidade, mas mantendo um padrão coletivo que não desafie a norma.

Nesse sentido, plasmamos o que deve ser a escuta de nossas/nossos alunas/alunos, moldamos, conforme as regulações dispositivas - traduzidas na escola como currículo -, o que deve ter ou não na aula de música, qual deve ser a condução do saber tecido em nossas relações cotidianas. Assim, desconsideramos uma maior possibilidade de interação entre as teias de relações sociais que a juventude fia com a cidade (VICTORIO FILHO, 2008), reforçamos a deslegitimação das práticas juvenis, suas atuações, suas performances e suas estéticas. Também desconsideramos a bicha como produtora/compartilhadora de saberes, de modo que, em nossas ações práticas curriculares, cada vez menos cabe determinadas escutas e estéticas.

\section{'Sou a Lia aqui no baile e vou mandando o proceder': jovens bichas, o funk LGBTTQIA+ e as tessituras curriculares}

Ao consideramos que o funk estabelece relações de visibilidade (estética, inclusive) para o público LGBTTQIA+, temos de considerar que também ocupa um status mal-dito na chamada música brasileira popular (FACINA, 2009). Não é incomum que vejamos críticas ao gênero, bem como a seus intérpretes, às suas letras e melodias, e às narrativas que são consideradas marginalizadas justamente por retratar um cotidiano vivido e experenciado por seus atores/atrizes sociais nos enredos de uma vida cercada de desigualdades e repressões, traduzidas, muitas vezes, de modo pragmático em suas estéticas. Certos que nossa fala não deve ser homogeneizante para descrever estruturas artísticas juvenis, caminhamos num sentido de unir os diversos sujeitos produtores do funk (intérpretes e ouvintes) ao que Victorio Filho (2008, p.217) chama de "estética da produção de suas vidas". Essas pessoas jovens, sobretudo as pertencentes às escolas públicas, ao consumirem essa música, (com)partilham suas identidades aos outros tantos agentes do processo educativo que no ambiente da escola estão presentes. Ali, na tessitura da trama, ao desenvolverem e se envolverem nas redes de saberes (ALVES, 2001), são os sujeitos ativos nos 
enredamentos e agenciamentos de seus saberes e não mais reprodutores dos dispositivos que antes cristalizavam os desenvolvimentos de suas escutas, estéticas e feituras artísticas.

Levando em consideração o lugar ocupado pela música funk LGBTQIA+ no universo escolar, precisamos, fazendo coro com as palavras de Silva (2012),

\begin{abstract}
Admitir que a escola é, entre muitas outras coisas, também um aparelho ideológico do Estado na manutenção de hegemonias, faz-se necessário. Obviamente, não somos integralmente condicionados por esse Estado, até porque nenhum poder pode tudo. [...] Claro que a escola não é "O" braço direito desse estado, mas é, sem dúvida, um território que, entre muitas outras coisas, faz também a manutenção-esforço-reprodução da violência estatal, ainda que seja esta uma violência discursiva e simbólica. Para isso, cria uma série de instrumentos para proceder com a punição simbólica, que é mito dura e marcante na vida de qualquer estudante de classes populares (SILVA, 2012, p.186).
\end{abstract}

Essa reprodução da violência é o retrato dos esforços - por parte daqueles que estão no poder - em normatizar uma sociedade para que o controle seja estabelecido, os limites demarcados e os corpos padronizados. A escola como instrumento e lugar de controle e disciplina, manipula corpos e exerce sobre eles uma "coerção sem folga, de [modo a] mantê-los ao nível mesmo da mecânica - movimentos, gestos, atitude, rapidez: poder infinitesimal sobre o corpo ativo" (FOUCAULT, 1999, p.118). Entendemos neste texto que há, portanto, uma maneira direta da escola criar seus instrumentos de coerção, na qual é possível atingir a público por inteiro: o currículo.

Arroyo (2011) mostra-nos que na construção espacial de um sistema escolar, o currículo integra o núcleo-centro estruturante funcional da escola, "por causa disso, é o território mais cercado, mais normatizado. Mas também o mais politizado, inovado, ressignificado" (Arroyo, 2011, p.13). Para indicar esse lugar ocupado pelo currículo na educação, o autor mostra-nos a quantidade de diretrizes curriculares para a educação básica, nas quais quando se propõe a diversidade nessas propostas, segundo ele, atesta-se a configuração política do poder sobre a escola. O currículo é um dos dispositivos para afirmação e validação desse controle, constrição disciplinar e regulação de aprendizagens.

O dispositivo, para Foucault (2014, p.364), é "um conjunto decididamente heterogêneo que engloba discursos, instituições, organizações arquitetônicas, decisões regulamentares, leis, medidas administrativas, enunciados científicos, proposições 
filosóficas, morais, filantrópicas". Nesse sentido, o dispositivo tem, portanto, "uma função estratégica dominante” (FOUCAULT, 2014, p. 365). Assim sendo, quando nos propomos a entender o currículo escolar como um dispositivo que controla, caminhamos no sentido de tentar enxergar os microcosmos presentes na macrocosmia das instituições educativas e empenhar-se para entender e "apreender o máximo possível - que na maioria das vezes parece ser o mínimo - dos processos, tramas e engendramentos, encontros e desencontros que instituem e constituem o universo escolar contemporâneo" (VICTORIO FILHO, 2005, p.2) e "como funcionam as coisas no nível do processo de sujeição ou dos processos contínuos e ininterruptos que sujeitam os corpos, dirigem os gestos, regem os comportamentos (FOUCAULT, 2014, p.283).

O dispositivo é um modo pelo qual se consolida a ação do poder, é uma transfiguração do poder e, partindo disso, ao focar no currículo da educação musical escolar, veremos que, como poder encarnado, este ingrediente potente da educação escolar formalizada pressupõe os fundamentos, as reflexões, percepções, sensações, técnicas, formas, estilos, ideias, julgamentos de belezas e tem o poder de determinar as escutas, os fazeres e saberes musicais na educação básica. É necessário ponderar, do mesmo modo, que esse poder não se concentra, a princípio, numa relação hierárquica, mas sim num círculo de redes que baliza o poder hierárquico. Ao formatar, o poder se deixa formatar, criando seus movimentos próprios e não sediando toda a sua força/ação em um centro de controle, mas sim, circulando.

Desse modo, quando pensamos no ambiente educativo formalizado, os indivíduos estruturam suas formas de ser/estar na escola e nos fazem perceber a materialidade do dispositivo e as formas de sua reprodutibilidade, ou seja, "o dispositivo garante a conversão dos traços em amplas cadeias de signos conforme os reproduz em diferentes superfícies. São, dessa maneira, exorcizados aos poucos os efeitos do acaso. São extintos os traços que não podem se aliar ao dispositivo" (JUNGER, 2015, p.79). Portanto, se os traços todos se ali(nh)am ao dispositivo, é possível entender que, nos cotidianos escolares, há diversas formas de praticar o dispositivo (e de pensá-lo).

Nos interessa considerar essas diversas formas de praticar, pensar e (re)fazer o conhecimento musical dentro da escola, enxergando minuciosamente os passos 
insurgentes de jovens LGBTTQIA+, que, ao utilizarem o funk como linguagem, recriam escutas e criam "uma estética própria e original, para além da outorga acadêmica, comercial ou dos mercados culturais" (VICTORIO FILHO, 2008, p.221). Esse ato de estetizar a vida, como nos mostra o autor, vai além de rebelar-se contra uma posição que a escola tenta fixar, ele é o movimento que institui uma tão importante ação reativa que entra pelas minúsculas frestas deixadas por esse poder que, como vimos, não pode tudo. Ao entrar, desloca o que é instituído - que consideramos ser o currículo como matriz geradora do poder institucional escolar - e cria fontes de saberes que, nesses espaços são (com)partilhados. Como nos assevera Victorio Filho (2008):

É a estética das performances individuais e coletivas, das danças, e modos de estar, de se apresentar e de agir, também individual e coletivamente, o que defendemos como inegável e potente criação e deflagração de saberes. Saberes que, entre outras provocações, desconcertam os regimes de valores-verdades vigentes sobre arte e a experiência estética.

Regimes, certamente, contaminados pela rede de interesses e crenças burguesas e pela tônica mercadológica que tem prevalecido em quase todas as mediações sociais (VICTORIO FILHO, 2008, p.222).

Essa (contra)produção de saberes desestabiliza o controle escolar assim como desestabiliza o que está por detrás dele, estremecendo conceitos cristalizados sobre o campo da educação e das relações dentro da escola e propriamente sobre a música "boa" ou "ruim", tão amplamente discutida pela área de Etnomusicologia. Sabemos que nossa tradição musical cultural é fortemente alicerçada nos parâmetros das escolas de música europeias, as instituições chamadas Conservatórios, um modelo educacional que prevê a formação técnica dos estudantes, e se pauta em moldes rígidos de leitura e escrita musicais, além de outras marcas que enrijecem e engessam a música na escola. Com a permissão do leitor, citamos Pereira (2014) que nos esclarece sobre esse modelo e as ações que ele ocasiona no ambiente escolar, com foco nas aulas de música:

- o ensino aos moldes do ofício medieval - o professor entendido, portanto, como mestre de ofício, exímio conhecedor de sua arte;

- o músico professor como objetivo final do processo educativo (artista que, por dominar a prática de sua arte, torna-se o mais indicado para ensiná-la);

- o individualismo no processo de ensino: princípio da aula individual com toda a progressão do conhecimento, técnica ou teórica, girando em torno da condição individual; a existência de um programa fixo de estudos, exercícios e peças (orientados do simples para o complexo) considerados de aprendizado obrigatório, estabelecidos como meta a ser alcançada; 
- o poder concentrado nas mãos do professor - apesar da distribuição dos conteúdos do programa se dar de acordo com o desenvolvimento individual do aluno, quem decide sobre este desenvolvimento individual é o professor;

- a música erudita ocidental como conhecimento oficial; a supremacia absoluta da música notada - abstração musical;

- a primazia da performance (prática instrumental/vocal);

- o desenvolvimento técnico voltado para o domínio instrumental/vocal com vistas ao virtuosismo; a subordinação das matérias teóricas em função da prática;

- o forte caráter seletivo dos estudantes, baseado no dogma do "talento inato" (PEREIRA, 2014, p.93).

Com essa citação - longa, porém, necessária - podemos exemplificar como o autor nos mostra vários elementos que orientam e integram a prática musical das escolas especializadas em música e na educação básica. Esses enrijecimentos da música na educação fazem com que haja uma desconsideração das práticas sonoras da cotidianidade e, por consequência, das várias manifestações musicais presentes nesses espaços, que acabam não sendo validadas e seus sujeitos produtores/consumidores acabam sendo marginalizados. Ou seja, essas ações fazem com que, ainda, haja uma produção cada vez mais intensa de dispositivos que controlam, punem e coagem os praticantes do cotidiano.

Ao pensarmos que "toda obra cultural, aceita como 'arte' ou não, oferece leituras sobra as diversidades e potencialidades dos grupos sociais que as produziram" (VICTORIO FILHO, 2008, p.217), caminharemos na direção de entender os motivos pelos quais essa estética consegue entrar na cultura musical escolar, mesmo que clandestinamente, pelas frestas deixadas pelos dispositivos. Lopes (2011) nos diz que o funk é a união entre música, dança e estilo, "marcas dessa cultura que desafia as fronteiras dos estado-nação com seus padrões de ética e estética” (LOPES, 2011, p.17), além de tirar proveito daquilo que é considerado como "lixo" ou "vulgar" na cultura moderna, segundo a autora. É, ao mesmo tempo, música, linguagem e cultura, "sobretudo uma prática historicamente situada: uma forma de cantar, de expressar, de construir de vivenciar e de sentir o mundo" (Idem, p.19).

O funk evidencia como a juventude negra e favelada se reinventa criativamente com os escassos recursos disponíveis, subvertendo, muitas vezes, as representações que insistem em situá-la como baixa e perigosa. Além disso, a crítica ao funk escancara a maneira pela qual a sociedade brasileira renova seu racismo e preconceito de classe camuflados pela retórica ocidental do "bom gosto estético" (LOPES, 2011, p.18). 
A estética funk produzida pelo e para o público LGBTTQIA+ narra a vida vivida, os cenários de milhares de jovens brasileiros e estrangeiros e os modos pelos quais criam e (re)inventam suas formas de existir e resistir dentro do plano social, que, ainda, marginaliza, massacra e assassina. Acreditamos que, na escola, essa estética ganha vida para tentar derrubar as imposições sexuais binárias que as ações curriculares enquadram a juventude, assim como numa reação, mesmo que inconsciente, às heranças tradicionalistas das políticas públicas educacionais, que ainda preservam padrões que não conseguem mais contemplar toda a diversidade presente na escola contemporânea.

É necessário ponderar que os "valores da masculinidade hegemônica instauraram representações sociais de saúde, beleza, sucesso e aceitação social" (MISKOLCI, 2006, p.684), portanto, quando pensamos na escola e nas suas práticas, políticas e processos, temos que imaginar que o indivíduo homem terá que assumir determinadas posturas nesse ambiente que farão com que, permanentemente, os padrões hegemônicos sejam mantidos. "Ou somos idênticos, ou nos denunciamos. E se nos denunciamos como diferentes nesse mundo de padrões tão rígidos, somo expostos a um preconceito crescente" (Ibidem). Também é necessário ponderar que dentro do próprio movimento funk, o público LGBTTQIA+ é, constantemente, marginalizado. Podemos considerar que os precursores de uma nova forma de pensar-fazer funk sejam MC Serginho e Lacraia, que, segundo Lopes (2011), carnavalizam as regras de gênero e ironizam a matriz heterossexual. A dupla funkeira foi responsável por quebrar os modelos existentes ao refutar a matriz geradora do estilo e subverter as regras, as lógicas e os usos que até então pareciam cristalizados. Esses artistas foram responsáveis pela criação, como mencionamos na primeira parte desse artigo, de uma estética da existência, assim chamada por Miskolci (2006).

A estética da existência é a forma pela qual há uma ruptura nos padrões normativos que foram responsáveis por configurar os padrões sociais, "desconstrói as representações sociais que criam e impõem identidades", "recusa o assujeitamento aos modelos de corpos e identidades socialmente impostos (MISKOLCI, 2006, p.690), "é uma forma de resistência que exige um esforço de desenraizamento, descorporificação, ou seja, de rejeição das oposições aprisionantes entre masculino e feminino, corpo e 
identidade" (Idem, p.691). Assim sendo, consideramos "que todo processo de criação estética é também produção de saberes" (VICTORIO FILHO, 2008, p.227) e, sendo produção de saberes, "como qualquer estética, a estética funk é política” (Idem, p.226).

Se procuramos entender que todo processo de formação estética e, do mesmo modo, de formação educacional em Arte, é político, consentimos que ele forma novos dispositivos e/ou reforça os já existentes. Os currículos escolares em Arte, como dispositivos que controlam e regulam saberes, corpos e sujeitos, afirmam constantemente um ideário artístico a ser ensinado-aprendido. Nessa direção, circunscritos nos dispositivos que se transfiguram nos currículos escolares e regulam nossa escuta, teremos uma distinção entre aquilo que pode ser ouvido e validado como educativo e aquilo que tem ou não valor cultural. Essa cilada que é composta, continua a ser pensada por classes dominantes para classes populares, o que "promovem e legitimam exclusões e assassinatos, físicos e simbólicos" que, ainda, no universo musical escolar "geram [...] preconceitos e dominações de repertórios e modeles de ensino canônicos, baseados, sobretudo, na imposição da cultural musical erudita europeia sobre outras formas de expressão musical” (QUEIROZ, 2017, p.100). Acreditamos, junto ao autor, que haja um epistemicídio musical, que é responsável, portanto, por tentar excluir as outras formas de pensar e fazer música por aqueles/aquelas que não estão ocupando a centralidade do poder.

Segundo Santos (1995), do genocídio, que eliminou os povos diferentes e marcou a expansão do território europeu, nasce o epistemicídio, que é uma forma de eliminação daquilo que não é considerado como parte integrante de uma determinada camada da sociedade. Para ele, a prática epistemicida foi mais avassaladora do que a genocida, "porque ocorreu sempre que se pretendeu subalternizar, subordinar, marginalizar, ou ilegalizar práticas e grupos sociais que podiam ameaçar a expansão capitalista" e, assim, manifesta-se "contra os trabalhadores, os índios, os negros, as mulheres e as minorias em geral (étnicas, religiosas, sexuais).” (SANTOS, 1995, p. $328)$.

Desse modo, auxiliados por Queiroz (2017), podemos chamar de epistemicídio musical as expressões musicais europeizadas, que, quando (e)levadas acima dos conhecimentos assassinam os saberes produzidos pelas camadas sociais que estão do 
lado de baixo da esfera do poder. De acordo com o autor, o epistemicídio musical marcou - e ainda marca - a prática e formação institucional da música no Brasil e, temos, como professores de música e formadores de formadores, responsabilidade de combater essas barreiras simbólicas, "que, pelas mortes simbólicas, são indutores e promotores de diversas outras matanças. Ao matar formas de pensar, formas de sentir, formas de ser e estar no mundo, formas de fazer e sentir músicas, se assassina sujeitos" (QUEIROZ, 2017, p.107).

Se voltarmos nossos olhos às práticas curriculares musicais na/da educação escolar, iremos perceber estranhamentos a outros fluxos culturais que divergem da rigidez imposta pelos movimentos epistemicidas. As práticas musicais da cotidianidade são, quase sempre, negligenciadas nos processos de tessituras de saberes dentro/fora de nossas escolas. Continuamos, portanto, a empregar o poder - simbólico e figadal - que controla, pune, limita, desmerece e que elide os diferentes por serem diferentes. Por esse ângulo,

Os Estudos do Cotidiano são, por essas razões, os meios mais adequados e menos lesivos de investigar o acontecimento funk em toda as suas linhas de fuga, na medida em que suas práticas investigativas são, por sua contemporaneidade e audácia epistemológica, esteticamente funk! (VICTORIO FILHO, 2008, p.218).

É importante - e caro - a nós, enquanto pesquisadoras/pesquisadores, observarmos que qualquer manifestação cotidiana na/da escola é parte integrante do currículo e, ao centralizarmos as ações cotidianas como parte das tessituras curriculares, iremos considera-los como como potências dos coletivos que consideram as singularidades, mas não anulam a multiplicidade, dando voz às invenções daqueles que os praticam no dia-a-dia escolar (FERRAÇO; CARVALHO, 2012). Na estética funk, principalmente ao público LGBTTQIA+, ao se tornarem insurgentes criando um currículo e aprendizagens cotidianas diferentes das diretrizes, esses sujeitos rompem com as normatividades presentes no espaço escolar e as estruturas que se encontram, ainda, sedimentadas e (des)regulam práticas pedagógicas e deslocam práticas identitárias. Criam, assim, um currículo - que entendemos ser a forma de existir no espaço escolar, para que a vida, nele, seja mais suportável, fruível, como nos ensina Victorio Filho (2005). 
Quando assumimos, num texto acadêmico, nosso posicionamento em relação ao funk, bem como damos visibilidade às produtoras e produtores dentro do espaço escolar, caminhamos na tentativa de entendermos de quais modos essas práticas musicais coadjuvam para uma estética da existência, ou seja, "levam à criação de novos estilos de vida baseados em uma ética capaz de criar subjetividades mais libertárias e, a partir delas, novas formas de sociabilidade” (MISKOLCI, 2006, p.689). Essa existência que transpõe a música e passa a ser corpo-identidade, é o enfrentamento pela resistência do público LGBTTQIA+ nos cotidianos escolares, resistência, até mesmo, pelo permanente movimento de tessitura de saberes foradentro/dentro-fora das escolas. Nessa direção ressaltamos que

Toda obra cultural, aceita como 'arte' ou não, oferece leituras sobre as diversidades e potencialidades dos grupos sociais que as produziram. Temos, então, nas produções 'Funk' um meio útil à elucidação do que faz parte expressiva da juventude ser o que é e enfrentar o que enfrenta. Útil, portanto, ao entendimento dos cenários juvenis brasileiros e suas aproximações e afastamentos (VICTORIO FILHO, 2008, p.218).

Ao olharmos para o currículo centrando nas ações dos sujeitos dos cotidianos, bem como, na ideia de uma tessitura de conhecimento por várias maneiras, perceberemos que estes mesmos sujeitos criam e (com)partilham uma rede de saberes que se (trans)formam em currículos e com eles (e por meio deles) vão desenvolvendo novos espaços/tempos de aprendizagem no dia-a-dia escolar, fugindo às imposições reguladoras de um conhecimento comum, como assevera Alves (1986 apud LOPES; MACEDO, 2005). Portanto, o currículo está em constante movimento nos pensamentos de seus praticantes, sendo articulados entre eles. Os currículos, nesta perspectiva, são considerados como potências dos coletivos que consideram as singularidades, mas não anulam a multiplicidade, dando voz às invenções daqueles que os praticam no dia-adia escolar (FERRAÇO; CARVALHO, 2012).

Assim sendo, observamos que, mesmo com o discurso de uma educação musical equitativa, o funk enquanto estética, fica longe dos holofotes dos dispositivos curriculares. Podemos pensar o currículo oficial escolar como dispositivo de controle de nossas práticas, uma vez que percebemos que há uma verticalização de saberes, ou seja, nem sempre os praticantes dos cotidianos escolares podem assumir participação efetiva nas decisões do que pode constar nos documentos que validam o que é o saber 
institucionalizado. Vemos, portanto, que a fugacidade dos cotidianos e suas práticas estéticas, não cabem nas regulações oficializadas.

\section{"Sororidade é o poder das mana": à guisa de uma finalização}

Escrever um texto acadêmico é, quase sempre, tentar uma linearidade, um começo-meio-fim. Entretanto, mais do que apresentar conclusões, este texto pretende levar às inquietações, levar aos questionamentos, levar aos debates que são, cotidianamente, silenciados. Ao escolher a música funk LGBTTQIA+, falar sobre as bichas na escola, os currículos e as práticas musicais/artísticas ainda controladas é um desafio. Desafio porque a bicha e sua música ocupa, na escola, não-lugares (AUGÉ, 2005), ocupa a clandestinidade, é, constantemente, incitada a estar num lugar marginalizado, com voz, mas inaudita.

A ideia da imoralidade, da linguagem mal-dita, das práticas de valor cultural inferior, fazem com que os currículos escolares estejam contaminados de visões que segregam práticas estéticas que representam uma emancipação para determinados grupos. Este trabalho pretendeu, sobretudo, questionar esses lugares que a música funk e a bicha ocupam nos currículos escolares. "Acreditamos que o território desprestigiado da juventude funkeira seria um excelente ponto de partida e/ou campo de luta" (VICTORIO FILHO, 2008, p.227), por este motivo, juntamos essa problematização inicial, para que novos debates sejam realizados posteriormente.

Do mesmo modo, acreditamos que "todo processo de criação estética é também de produção de saberes" (VICTORIO FILHO, 2008, p.227) e, quando traçamos um mapeamento sobre os saberes escolares na cotidianidade, veremos que as bichas têm, em muito, o que contribuir com nosso discurso. O campo de tensões presente na interseção entre juventude, funk, currículos e cultura escolar é o que nos interessa pensar, tomando cuidado para não fazer uma crítica molesta à escola, sobretudo as públicas. Assim sendo, percebemos que ainda há silenciamentos, distanciamentos, controles e coações. Portanto, ao colocar em debate esses caros assuntos à educação musical - mesmo não sendo, ainda, abordados amplamente pela área - interrogamos seu papel no cotidiano escolar e sua pretensa intenção de democratizar o seu acesso e ensino. 
Diagramar as estéticas insurgentes de jovens bichas e falar sobre suas músicas, é sublinhar sua efemeridade e potência. Efemeridade que causa (trans)formação constante, movimento, potência que ensina que nenhum poder pode tudo e, em suas fendas, a fruição acontece. Acreditamos que nossos rascunhos iniciais são portas de entrada para outros estudos, e ampliação deste. Assim, evidenciamos que a estética funk LGBTTQIA+ é uma estética da existência (MISKOLCI, 2006), que faz com que esses jovens tenham, no espaço escolar, condições de (sobre)vivência e, a partir de suas produções musicais, lutem por um escola e "por uma sociedade mais justa e uma vida mais bela" (VICTORIO FILHO, 2008, p.228).

\section{REFERÊNCIAS}

ALVES, Nilda; OLIVEIRA, Inês Barbosa de. Pesquisa no/do cotidiano das escolas: sobre redes de saberes. Rio de Janeiro: DP\&A, 2001.

ALVES, Nilda. Decifrando o pergaminho - o cotidiano das escolas nas lógicas das redes cotidianas. In: Oliveira, Inês Barbosa; Alves, Nilda. (Org.). Pesquisa no/do cotidiano das escolas: sobre redes de saberes. Rio de Janeiro: DP\&A, 2001.

Algebaile, Eveline Bertino. Escola Pública e Pobreza: expansão da escola dos pobres no Brasil. Tese (Doutorado) Programa de Pós-Graduação em Educação da Universidade Federal Fluminense. Niterói/RJ, 2004.

ARROYO, Margarete (Org.); NASCIMENTO, Thais Vieira; JANZEN, Thenille Braun (Colaboradoras). Jovens e músicas: um guia bibliográfico. São Paulo: Editora Unesp, 2013.

ARROYO, Miguel. Currículo, território em disputa. Petrópolis: Vozes, 2011.

AUGÉ, Marc. Não-lugares: Introdução a uma antropologia da Sobremodernidade. Lisboa: 90 Graus, 2005.

CARLOS, Ana Fani Alessandri. O lugar no/do mundo. São Paulo: FFLCH, 2007. 
CERTEAU, Michel. A invenção do cotidiano: 1, Artes de fazer. Petrópolis: Vozes, 1998.

DAYRELL, Juarez. O rap e o funk na socialização da juventude. Educação e Pesquisa, São Paulo, v.28, n.1, p. 117-136, jan./jun. 2002.

FACINA, Adriana. "Não me bate doutor": Funk e criminalização da pobreza. Anais... V Enecult - Encontro de Estudos Multidisciplinares em Cultura. Salvador, 2009.

FERRAÇO, Carlos Eduardo; CARVALHO, Janete Magalhães. Currículo, Cotidiano e Conversações. Revista E-Curriculum, São Paulo, v.8 n.2, Ago. 2012.

FOUCAULT, Michel. Vigiar e Punir: nascimento da prisão. Tradução de Raquel Ramalhete. Petrópolis: Vozes, 1999.

- Microfísica do Poder. Organização, introdução e revisão de Roberto Machado. 28 ed. Rio de Janeiro: Paz e Terra, 2014.

HALL, Stuart. A identidade cultural na pós-modernidade. Tradução: Tomaz Tadeu da Silva, Guaraciara Lopes Louro. 11ª edição. Rio de Janeiro: DP\&A, 2006.

JUNGER, Victor. Acontecimento-Escola: Entrecruzamentos do Fotográfico, artístico e pedagógico. Dissertação (Mestrado) Programa de Pós-Graduação em Artes da Universidade Estadual do Rio de Janeiro/UERJ, 2015.

LOPES, Alice Cassimiro; MACEDO, Elizabeth (Orgs.). Currículo: Debates

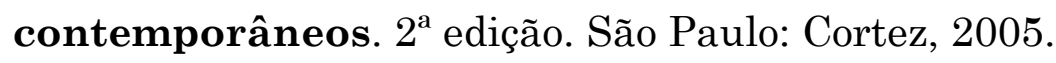

LOPES, Adriana Carvalho. Funk-se quem quiser: no batidão negro da cidade carioca. Rio de Janeiro: Bom Texto: FAPERJ, 2011.

MISKOLCI, Richard. Corpos elétricos: do assujeitamento à estética da existência. Disponível em: <www.scielo.br/scielo.php?script=sci_arttext\&pid=S0104-26X2006000300006\&lng=\&nrm=iso >. Acesso em: 10 de jul. Estudos Feministas, Florianópolis, setembro-dezembro. 2006.

OLIVEIRA, Megg Rayara Gomes de. O diabo em forma de gente: (R)Existências de gays afeminados, viados e bichas pretas na educação. Tese (Doutorado) Programa de Pós-Graduação em Educação da Universidade Federal do Paraná. Curitiba/PR, 2017. 
PEREIRA, Marcus Vinícius Medeiros. Licenciatura em música e habitus conservatorial: analisando o currículo. Revista da Associação Brasileira de Educação Musical (ABEM), v.22, n.32, p.90-103, jan-jun, 2014.

QUEIROZ, Luis Ricardo Silva. Formação intercultural em música: perspectivas para uma pedagogia do conflito e a erradicação de epistemicídios musicais. InterMeio: Revista do Programa de Pós-Graduação em Educação, Campo Grande, v. 23, n. 45, p. 99-124, 2017.

REIS, Toni; EGGERT, Edla. Ideologia de Gênero: uma falácia construída sobre os planos de Educação brasileiros. Educação \& Sociedade, Campinas, v. 38, nº 138 , p.9-26, jan.-mar., 2017.

SANTOS, Boaventura de Sousa. Pela Mão de Alice: o social e o político na pósmodernidade. São Paulo: Cortez Editora, 1995.

SILVA, Rodrigo Torquato da. Escola-Favela e Favela-Escola: "esse menino não tem jeito!" Petrópolis: DP\&A, São Paulo: Cortez, 2005.

TAKARA, Samilo. Uma pedagogia bicha: homofobia, jornalismo e educação. Tese (Doutorado) - Programa de Pós-Graduação em Educação da Universidade Estadual de Maringá. Maringá/PR, 2017a.

TAKARA, Samilo. "Que que é isso que essas bichas tão fazendo?" Micropolíticas de resistência em enviadescer da Mc Linn da Quebrada. Anais... $7^{\circ}$ Seminário Brasileiro de Estudos Culturais e Educação/4º Seminário Internacional de Estudos Culturais e Educação. Canoas/RS, 2017b.

TAKARA, Samilo. Histórias de meninos afeminados: resistência e política nas leituras de artefatos culturais. Revista Entrelaces, v.2, nº 9, Jan-Jun, 2017c.

VEIGA, Cynthia Greive. Escola pública para os negros e os pobres no Brasil: uma invenção imperial. Revista Brasileira de Educação, vol. 13, núm. 39, set-dez, 2008. VICTORIO FILHO, Aldo. A Arte na educação: A invenção da escola cotidiana. Tese (Doutorado) Programa de Pós-Graduação em Educação da Universidade do Estado do Rio de Janeiro. Rio de Janeiro, 2005.

VICTORIO FILHO, Aldo. Estéticas nômades: outras histórias, outras estéticas, outros...ou o funk carioca: produção estética, epistemológica e acontecimento. Revista 
Visualidades. Disponível em < https://doi.org/10.5216/vis.v6i1ei2.18085 > Acesso em $21 / 05 / 2018$.

Recebido em agosto de 2018.

Aprovado em outubro de 2018.

Publicado em dezembro de 2018. 